\title{
UNA APROXIMACIÓN CONTINENTAL AL DERECHO INGLÉS DE LOS CONTRATOS*
}

\author{
Alberto Pino Emhart \\ University of Oxford
}

John Cartwright, Contract Law. An Introduction to the English Law of Contract for the Civil Lawyer, $2^{\mathrm{a}}$ ed., Oxford, Hart Publishing, $2013(£ 25.00)$

\section{INTRODUCCIÓN}

En 2007, John Cartwright publicó la primera edición de su Introducción al Derecho inglés de los contratos dirigida especialmente a abogados provenientes de tradiciones jurídicas continentales. Recientemente en 2013, ha publicado una segunda edición de la obra, actualizando la jurisprudencia y doctrina relevante. Sin duda, se trata de un trabajo ineludible para cualquiera que pretenda estudiar el Derecho inglés de los contratos, especialmente para quienes provienen de una tradición jurídica continental o 'civil', como se le denomina en el contexto anglosajón ${ }^{1}$. En poco menos de

*Agradezco los excelentes comentarios que recibí de Rodrigo Momberg Uribe, Esteban Pereira Fredes e Isabel Zuloaga Ríos a un borrador de este trabajo. Cualquier error que permanezca es de exclusiva responsabilidad mía.

${ }^{1}$ Se le denomina tradición jurídica civil para destacar su raigambre en el Derecho Romano. trescientas páginas, logra dar una explicación clara y coherente de los principios que rigen el Derecho Contractual en el sistema inglés, destacando de modo especial los aspectos en los cuales dicho sistema se distancia de la mayor parte de los sistemas continentales, y las razones que justifican dichos distanciamientos.

Mi propósito en este breve comentario no consiste en revisar sistemáticamente cada uno de los aspectos del Derecho de los Contratos detallados en el libro. Sólo pretendo comentar algunos rasgos que resultan particularmente distanciados del sistema jurídico chileno, explicando las razones por las cuales estas diferencias se justifican en el sistema inglés. Este enfoque permite centrar la discusión en las diversas formas de solucionar los problemas contractuales, lo cual ayuda a realizar una comparación crítica de estas soluciones. Además,comentando este trabajo de John Cartwright espero demostrar que, a pesar de no tener una estructura sistematizada en un código, el Derecho inglés de los contratos tiene reglas claras y precisas, desarrolladas principalmente por la jurisprudencia. Por último, y en subsidio de lo anterior, mi intención es generar el interés 
del lector en la obra de John Cartwright, y en el Derecho Privado inglés en general.

\section{LOS CONTRATOS EN EL COMMON LAW}

Como primera aproximación a la materia, cabe señalar que la obra, objeto de este comentario, se centra en el Derecho inglés de los contratos (no existe un derecho británico de los contratos), que incluye tanto las jurisdicciones de Inglaterra como de Gales. Si bien otros sistemas jurídicos del Common Law siguen muy de cerca al sistema inglés (como en los casos de Irlanda, Canadá o Nueva Zelanda), otros ordenamientos han ido desarrollándose con independencia del sistema inglés (como Australia o Estados Unidos). 234 Respecto al ámbito contractual, en algunos casos las diferencias entre estos distintos sistemas pueden reducirse a meros detalles. Sin embargo, en otros casos puede haber diferencias más fundamentales como, por ejemplo, respecto al papel que ejerce el concepto de buena fe en la etapa de cumplimiento de los contratos, noción que ha tenido un mayor desarrollo en la jurisprudencia norteamericana $\mathrm{y}$ australiana (p. 10).

No obstante, algunas características generales son compartidas por todos los sistemas del Common Law. La característica más obvia es que todos estos sistemas derivan del sistema jurídico inglés $y$, como ya he indicado, muchos de ellos han ido formulando sus propias reglas. Otra característica central destacada por John Cartwright es el método utilizado para resolver casos en el Common Law, que consiste en analizar detalladamente los hechos particulares y las decisiones judiciales previas sobre la materia (p. 12). El abogado del Common Law no busca principios generales ni sistematizaciones, como podría encontrarse en un código, sino busca casos decididos con anterioridad que se asemejen a la situación fáctica en cuestión. Como consecuencia de ello, se entiende que la fuente principal de Derecho en estos sistemas sean los casos (case-law) o precedentes, sin perjuicio de que el legislador en ocasiones pueda intervenir para modificar las reglas asentadas en casos previos. Por esto es que la ley también es una fuente de Derecho en estos sistemas jurídicos. Otra consecuencia de este enfoque basado en decisiones judiciales previas por sobre las categorías jurídicas conceptuales es la importancia que tiene el papel del juez como creador del Derecho.

Dentro del Common Law, los contratos se sitúan en el ámbito del Derecho de las Obligaciones, en contraposición a la responsabilidad extracontractual (tort law) y el enriquecimiento injustificado (unjust enrichment). Por tratarse el enriquecimiento injustificado de una categoría jurídica desarrollada por la doctrina en forma reciente (durante alrededor de los últimos treinta años), puede señalarse que la estructura básica del Derecho Privado en el Common Law comparte con los sistemas jurídicos continentales la base romana que distingue entre aquellas obligaciones cuyo origen proviene de una relación convencional previa, y aquéllas en que no existe dicha conexión previa. Sin embargo, no hay una sistematización 
del Derecho Privado en general, y tradicionalmente en las escuelas de Derecho estas materias se estudian por separado. No obstante el esfuerzo por parte de algunos autores de articular una noción transversal de Derecho Privado, que incluya tanto las categorías del Derecho de Propiedad como de Obligaciones².

III. Dos PUNTOS DE PARTIDA: CONTRATOS ESPECIALES Y LA BUENA FE

De todas las características generales del Derecho inglés de los contratos identificados por John Cartwright, cabe destacar dos aspectos centrales que pueden considerarse como puntos de partida del sistema inglés. En primer lugar, puede mencionarse la escasa o limitada relevancia que tiene para el Derecho inglés la distinción entre contratos en general y contratos especiales (p. 56). Lo anterior es una consecuencia de lo explicado en la sección anterior: que los principios del Derecho de los Contratos han sido desarrollados principalmente por decisiones judiciales, de modo que dichos principios son aplicables en general a todos los contratos. No obstante, en algunos casos el legislador interviene para modificar respecto de un contrato especial estos principios generales. En consecuencia, pareciera ser que determinar en un caso particular de qué tipo de contrato se trata cumple un papel relevante en el sistema inglés, de manera similar a nuestro sistema. Sin embargo, John Cartwright sostiene que

\footnotetext{
${ }^{2}$ Ejemplos de estos esfuerzos pueden encontrarse en BURROws (2013) y WEINRIB (2012).
}

la pregunta acerca del tipo de contrato involucrado no forma parte del análisis rutinario del abogado formado en el Common Law. A pesar de que determinar la calificación del contrato en cuestión puede servir de alguna utilidad, las reglas aplicables a los contratos especiales son más limitadas en la práctica de lo que a primera vista pudiera parecer (p. 58).

El carácter excepcional de estas reglas para contratos especiales puede apreciarse examinando algunas de estas reglas especiales. En primer término, en la etapa de formación del contrato algunas reglas son aplicables sólo a algunos tipos de contratos como, por ejemplo, la exigencia de determinados requisitos especiales para la contratación de créditos de consumo $^{3}$, o la exigencia de celebrar por escrito en un solo documento firmado por todas las partes aquellos contratos que involucren la venta o, bien, cualquier otra enajenación de algún interés sobre un inmueble ${ }^{4}$. Asimismo, en aquellos contratos de venta comercial de bienes o servicios la legislación establece la presencia de ciertas específicas 'cláusulas implícitas' (implied terms). En la venta comercial de bienes, se entiende que los bienes son de 'calidad satisfactoria', ${ }^{5}$ mientras que en la venta comercial de servicios, se entiende que los servicios serán proveídos con un estándar de diligencia razonable ${ }^{6}$. Estas cláusulas equivalen a los elementos de la na-

${ }^{3}$ Consumer Credit Act 1974 part V.

${ }^{4}$ Law of Property (Miscellaneous Provisions) Act 1989 section 2.

${ }^{5}$ Sale of Goods Act 1979 section 14(2).

${ }^{6}$ Supply of Goods and Services Act 1982 section 13. 
turaleza de nuestro sistema jurídico, que se entienden incorporados sin necesidad de una cláusula especial (arts. 1444 y 1546 del CC). La diferencia radica en que nuestro sistema jurídico reconoce tanto elementos de la naturaleza aplicables tanto a una amplia gama de contratos (por ejemplo, la condición resolutoria tácita, que se entiende incorporada en todo contrato bilateral), como al caso específico de algunos contratos (véase la obligación de saneamiento, aplicable sólo al contrato de compraventa). En el Derecho inglés en cambio, las cláusulas implícitas sólo se entienden incorporadas en los contratos ya mencionados. De manera tal que en estos casos es determinante clasificar los contratos en cuestión.

Una interesante consecuencia prác236 tica del enfoque general de los contratos que adopta el sistema inglés tiene que ver con la redacción de los contratos. Dada la escasa regulación especial que tienen los contratos en el Derecho inglés, las partes usualmente buscarán precisar los términos del contrato de la manera más precisa posible, disminuyendo al máximo cualquier espacio para la interpretación o intervención judicial. Ello explica la razón por la cual podríamos esperar que los contratos redactados en Inglaterra sean más extensos y detallados que aquellos contratos redactados en un sistema continental, donde las partes pueden confiar en la regulación especial y someterse a cláusulas estándar del contrato en cuestión.

El segundo importante punto de partida destacado por John Cartwright es el principio de buena fe. La diferencia radical del sistema inglés de contratos con la mayor parte de los siste- mas continentales consiste en la inexistencia del principio de buena fe tanto para la celebración como para el cumplimiento de los contratos (p. 61). El sistema inglés no contempla un principio general de buena fe contractual como el del art. 1546 de nuestro Código Civil. Ello no obsta a que el ordenamiento solucione algunos problemas derivados de la mala fe de cualquiera de los contratantes mediante otros mecanismos distintos a la exigencia de buena fe. Esto refleja la naturaleza casuística del Common Law y su rechazo a adoptar principios generales, prefiriendo -en palabras de Lord Bingham (Thomas Henry Bingham) - distintas 'soluciones particulares (piecemeal solutions) como respuesta a situaciones de injusticia manifiesta'7. De manera tal que en ocasiones el Derecho inglés prefiere regular caso a caso aquellas situaciones que en un sistema continental se verían normalmente cubiertas por el principio de buena fe contractual. Otra razón que se ha esgrimido para rechazar el principio general de buena fe contractual es la falta de certeza para definir el contenido de dicho principio en una relación contractual (p. 63). Aun cuando las partes expresamente señalan el deber de negociar o cumplir un contrato de buena fe, dicho lenguaje es considerado ajeno al sistema contractual inglés, por lo cual se suele preferir el lenguaje de 'equidad' (fairness) y 'razonabilidad' (reasonableness). Sin embargo, advierte John Cartwright que esta tendencia podría estar cambiando durante los

${ }^{7}$ Interfoto Picture Library Ltd v Stiletto Visual Programmes Ltd [1989] QB 433 (CA) 439. 
últimos años. Incluso, en una reciente decisión de primera instancia, se ha señalado:

"la aprensión según la cual reconocer un deber de buena fe podría generar excesiva incerteza no se justifica. El concepto nada tiene de indebidamente vago o inoperable. Su aplicación no agrega mayor incerteza inherente al proceso de interpretación contractual. (...) Respetuosamente sugiero que, en la medida que aún persista, la tradicional hostilidad inglesa respecto a la buena fe en el cumplimiento de los contratos resulta inadecuada"

Otra interesante razón para justificar la 'tradicional hostilidad inglesa' al principio de buena fe tiene que ver con la concepción adversarial de las partes que el Derecho inglés adopta durante la etapa de negociación de los contratos:

"el concepto de un deber de llevar a cabo negociaciones de buena fe repugna inherentemente a la posición adversarial de las partes involucradas en las negociaciones".

Con todo, tratándose de algunos contratos específicos de carácter cooperativo como, por ejemplo, los contratos

\footnotetext{
${ }^{8}$ Yam Seng Pte Ltd v International Trade Corp Ltd [2013] EWHC 111 (QB), [2013] 1 Lloyds's Rep 526, [153] y [154].

${ }^{9}$ Walford v Miles [1992] 2 AC 128 (HL) 138.
}

de seguros o de sociedades, los tribunales han aceptado la existencia de deberes de buena fe implícitos y expresos tanto en la etapa de formación de estos contratos como en su cumplimiento (p. 64).

Sin perjuicio de lo anterior, a pesar de no reconocer un deber general de buena fe, el Derecho inglés adopta algunas de las mencionadas soluciones particulares que se asemejan a las soluciones genéricas de los sistemas jurídicos continentales. Cabe preguntarse, en consecuencia, si la diferencia entre ambos sistemas sólo se reduce a diferentes métodos de clasificación doctrinarias. La respuesta es negativa, puesto que, como se verá más adelante, el Derecho inglés adopta soluciones distintas a los sistemas continentales como resultado de no reconocer un principio general de buena

\section{RESPONSABILIDAD PRECONTRACTUAL}

Los manuales de Derecho inglés de los contratos normalmente no incluyen capítulos sobre responsabilidad por ruptura de tratativas preliminares de un contrato. El libro de John Cartwright, por el contrario, dedica un capítulo completo a la materia. Ello se justifica en el hecho de que el Derecho inglés adopta una perspectiva más conservadora que el Derecho Continental, siendo, incluso, el sistema más conservador dentro de los sistemas de Common Law en este aspecto (p. 71). 
En efecto, el punto de partida del Derecho inglés resalta de inmediato: no hay un deber implícito de buena fe, lealtad o cooperación entre las partes que negocian un contrato. Los tribunales, en pocas ocasiones, han rechazado la validez de acuerdos expresos para negociar de buena fe. Desde luego, en algunas situaciones el sistema inglés otorga acciones de responsabilidad civil a favor de la víctima defraudada en la negociación. Pero la regla general sigue siendo la inexistencia de un deber general de buena fe en la preparación del contrato. Si bien es cierto que en el sistema chileno el Código Civil no reconoce expresamente la existencia de este deber, tanto la doctrina como jurisprudencia han desarrollado este principio, reconociendo la existencia 238 de un deber de buena fe tanto en la etapa de preparación del contrato como de su cumplimiento, cubriendo todo el iter contractual. Así, v.gr., la CS ha señalado recientemente:

"entre los deberes precontractuales de quienes participan de las tratativas preliminares está el deber de lealtad, que exige llevar adelante las negociaciones de buena fe, esto es, con el propósito efectivo de celebrar un contrato; y que también suponen deberes de cuidado al terminar la negociación, cuando se ha creado en la contraparte la confianza de que se celebrará el contrato"10.

${ }^{10}$ Jiménez Mira, David Alejandro con Armijo Cerda, Antonio (Corte Suprema, casación en el fondo, 29 de diciembre de

Las razones que justifican el enfoque inglés sobre las tratativas preliminares son las mismas que justifican su rechazo a la existencia de un deber general de buena fe contractual: la reticencia del Common Law a consagrar principios generales, la incerteza acerca del contenido exacto del principio de buena fe, y la principal de ellas, que consiste en la concepción adversarial de las partes negociantes, según la cual el riesgo de que las negociaciones se quiebren pertenece a cada una de las partes hasta el momento de la celebración efectiva del contrato. Esta perspectiva adversarial de las partes explica también la razón por la cual el Derecho inglés no reconoce un deber general para las partes de informar, incluso, en aquellos casos en que un contratante sabe que la contraparte desconoce información relevante que podría afectar su decisión de contratar (p. 77). Sin embargo, nada obsta a que en algunas circunstancias el Derecho inglés reconozca deberes de informar a la contraparte $u$ otorgue incentivos a las partes para revelar información relevante.

$\mathrm{Al}$ igual que en el sistema chileno, en el Derecho inglés la mayoría de las (excepcionales) acciones de responsabilidad precontractual son de naturaleza extracontractual (tort (awe) ${ }^{11}$. En particular, el sistema inglés contempla dos tipos de ilícitos civiles no diseñados específicamente para el quiebre de tratativas preliminares de

2011, rol N 1872-2010), considerando tercero sentencia de reemplazo.

${ }^{11}$ A menos, desde luego, que las partes hayan regulado expresamente las negociaciones preliminares. Barros Bourie (2006), pp. 1003-1004. 
un contrato, pero que cubren algunas de estas situaciones. Se trata de las figuras del 'engaño'(deceit) y 'negligencia' (negligence). En el ilícito del engaño, todo aquél que fraudulentamente provea información falsa o distorsionada (fraudulent misrepresentation) a otro, con la intención de que éste actúe sobre la base de dicha información errónea, debe compensar los daños sufridos por la víctima como consecuencia de ello. Cabe señalar que para configurar este ilícito es requisito esencial demostrar la conducta fraudulenta (dolo). En este sentido, no es suficiente con probar que el demandado omitió señalar información relevante. En el ámbito precontractual, el daño indemnizable consistiría en los gastos en que uno de los contratantes puede incurrir basado en cualquier expresión o conducta del otro contratante que comunica una información falsa (p. 80). John Cartwright nos provee de ejemplos concretos en que esto puede ocurrir: la conducta de uno de los contratantes puede inducir a la contraparte a comenzar o continuar negociaciones, cuando en la práctica no tenía intención alguna de celebrar el contrato, o cuando se encuentra en negociaciones paralelas con otra potencial contraparte pretendiendo que no hay tal negociación. Por otra parte, el ilícito de negligencia puede cubrir situaciones en las cuales no hay conducta fraudulenta. Para ello, sin embargo, el demandante deberá probar que el demandado infringió un deber de cuidado respecto al demandante, lo que implica demostrar la existencia previa de un deber de cuidado entre las partes negociantes. Por regla general, no existe este deber de cuidado. Con todo, se ha estimado que aquél existiría en el evento en que la posición relativa de las partes permita entender que el demandante tiene derecho a confiar en lo que el demandado le ha señalado sin necesidad de comprobar la veracidad de lo informado. Esto ocurre sólo excepcionalmente, en la medida que una de las partes realice afirmaciones en su calidad de especialista o experto en el área, y que razonablemente induzca a la contraparte a confiar y actuar basándose en dichas afirmaciones (p. 81).

Existen otros mecanismos mediante los cuales el sistema inglés otorga acciones para recuperar daños derivados de la ruptura de tratativas preliminares que no son detallados en el presente comentario. Sólo cabe mencionar la posibilidad de que las partes regulen las negociaciones preliminares mediante acuerdos expresos, estableciendo hipótesis de responsabilidad contractual ${ }^{12}$. También menciona John Cartwright aquellos contratos de licitación en que se establecen crite-

${ }^{12}$ Resulta interesante discutir la validez que tendrían algunos de estos acuerdos, específicamente el 'contrato de opción' (option contract) y el 'derecho de preferencia' (right of preemption), en el sistema jurídico chileno, toda vez que se trataría de obligaciones contraídas bajo una condición potestativa que consiste en la mera voluntad de una de las partes (art. 1478 del $C$ C). En el contrato de opción, la condición dependería de la voluntad de quien acepta la oferta, mientras que en el derecho de preferencia la condición dependería de la voluntad de quien realiza la oferta. Sin embargo, el artículo 1823 del Código Civilpermite la celebración de una especie de contrato de opción en el contexto del contrato de compraventa, mediante la figura de la venta al gusto o a prueba. 
rios objetivos (u objetivamente determinables) para la adjudicación, en cuyo caso la licitación constituye una oferta que se entiende aceptada por quien realiza la mejor oferta de acuerdo con los criterios de la licitación. Por último, el sistema inglés, mediante los principios de enriquecimiento injustificado, también contempla la posibilidad para el demandante de solicitar la restitución del valor que equivalga a cualquier beneficio que el demandado haya obtenido durante las negociaciones preliminares. John Cartwright advierte, sin embargo, que la jurisprudencia no está del todo asentada respecto a esta materia. Pero hay jurisprudencia que ha ordenado la restitución de aquellos trabajos realizados durante estas negociaciones que no tenían la intención de ser gratuitos.

\section{LA DOCTRINA DE LA CONSIDERATION}

La doctrina de la consideration probablemente es la institución más característica del Derecho inglés de los contratos. Dicha doctrina determina qué tipo de acuerdos se regulan bajo el estatuto jurídico de los contratos, otorgándoles a dichos acuerdos la protección que les corresponde como tales. Los sistemas continentales de Derecho Civil normalmente establecen exigencias para este mismo efecto. Así, v.gr., nuestro Código Civil establece que los contratos deben tener objeto y causa. La doctrina de la consideration sostiene que una promesa de $\mathrm{A}$ a $\mathrm{B}$ es contractualmente válida sólo si $\mathrm{B}$ (el beneficiario de la promesa) ha hecho o promete hacer algo en beneficio de $\mathrm{A}$ (el promitente) como contrapartida (p. 127). De manera tal que dicha doctrina permite al Derecho inglés concebir la idea del contrato necesariamente como una negociación (bargain). Como consecuencia de esto, los contratos a título gratuito se encuentran excluidos del ámbito contractual inglés. Lo que no implica que la promesa de una donación no pueda ser legalmente ejecutable, toda vez que ha sido celebrada cumpliendo la formalidad del deed, que es una transacción formal empleada para distintos propósitos. Si bien es cierto que, como ha señalado Jorge López Santa María ${ }^{13}$, los deeds podrían ser considerados como contratos en los términos de un sistema jurídico continental, cabe señalar que para el Common Law los deeds no constituyen contratos; una donación es ejecutable sólo en virtud del deed, cuyas normas, en ocasiones, van más allá de las reglas que regulan los contratos (p. 123). De manera tal que el Derecho inglés no priva de protección las transacciones gratuitas; solo las excluye del ámbito contractual. Por ello, resulta interesante comprender la doctrina de la consideration, la cual determina que algunas transacciones entre particulares (aquéllas en que no hay contraprestación económicamente avaluable) no ameritan la intervención del Derecho de los Contratos. En consecuencia, no se trata de que

13 "Es comprensible que para el jurista medio, formado en la tradición continental del Civil Law, esta figura más bien parezca una expresión de la promesa unilateral como fuente de obligaciones, pero cuesta entender que un preclaro comparatista, como es David, niegue el carácter contractual del contrato bajo sello". López Santa María (2010a), p. 62. 
el Derecho inglés tenga "un profundo carácter formal", como sugiere Jorge López Santa María ${ }^{14}$. Se trata, más bien, de determinar cuáles transacciones deben permanecer entre privados sin requerir la intervención del aparato jurídico (sin perjuicio de que existan otros mecanismos, como los deeds, para asegurar el cumplimiento de estas transacciones) y cuáles efectivamente merecen la tutela del estatuto jurídico de los contratos.

La doctrina de la consideration tiene algunas reglas especiales. La primera de ellas sostiene que $B$ (el beneficiario) provee de consideration si ha hecho, o promete hacer, algo a solicitud de A. De esta regla se desprende que $\mathrm{B}$ no necesita dar o hacer algo, sólo basta con que se comprometa a dar o hacer algo como contrapartida. Asimismo, la acción o promesa de $\mathrm{B}$ debe ser realizada a solicitud de A, excluyendo de tal manera actos o promesas espontáneos por parte de B. Adicionalmente, se ha estimado que no hacer o prometer no hacer algo constituye consideration siempre que se cumplan los demás requisitos. Un ejemplo paradigmático de esto último es el acuerdo extrajudicial, en el cual el demandante renuncia a su derecho a demandar o a continuar con su demanda.

La segunda regla especial señala que hay consideration siempre que $\mathrm{B}$ haga o prometa hacer algo que implique un detrimento tanto para $\mathrm{B}$ como un beneficio para $\mathrm{A}$. Esta regla incluye la situación normal de un contrato. Así, v.gr., hay consideration cuando B paga $\$ 1.000 .000$ por el auto de A, toda vez que el pago de $B$ es un detrimen-

\footnotetext{
${ }^{14}$ López Santa María (2010a), p. 60.
}

to para éste, y al mismo tiempo hay un beneficio para $\mathrm{A}$, que consiste en recibir el pago de la suma de dinero. Pero la regla también incluye situaciones contractuales menos habituales. Por ejemplo, si A se compromete a transferir su auto a $\mathrm{B}$ siempre que este último le pague $\$ 1.000 .000$ a C. En tal evento, el hecho de que la suma de dinero se pague a una tercera persona (C) no obsta a que exista consideration, toda vez que es suficiente con que B sufra un detrimento como contrapartida de la obligación de $\mathrm{A}$, sin que sea necesario indagar cuál sería el beneficio para $\mathrm{A}$.

La tercera regla especial de la consideration prescribe que el acto o promesa de $B$ debe tener algún valor económico. Dicho acto o promesa no necesita ser el pago de una suma de dinero, pero debe ser susceptible de avaluación económica. Los deberes morales, en consecuencia, se encuentran excluidos de la consideration. Sin embargo, este hecho no implica que los tribunales deban evaluar si la negociación entre las partes es equitativa considerando el valor económico de las obligaciones. Por ello es que, incluso, se ha estimado que el pago de una renta anual de $£ 1$ por el arriendo de una propiedad constituye consideration ${ }^{15}$. Esto no se explica porque al Common Law no le interese en lo absoluto la equidad de las obligaciones recíprocas de las partes. La razón es que la equidad no es un elemento relevante para efectos de determinar si hay consideration o no, sin perjuicio de que los tribunales pueden tomar en

${ }^{15}$ Thomas v Thomas (1842) 2 QB 851, 114 ER 330. 
cuenta este factor para determinar si la parte dominante ejerció una 'influencia indebida' (undue influence) para celebrar el contrato, o si el contrato puede ser calificado como un 'negocio desmedido' (unconscionable bargain). A mayor abundamiento, cabe señalar que las partes pueden utilizar esta regla para asegurarse de que un acto gratuito sea calificado como un contrato y obtenga protección como tal. En este sentido, las partes pueden establecer una consideration nominal, pagando notoriamente bajas sumas de dinero (como $£ 1)$ o, incluso, un grano de pimienta. Ello resulta sorprendente para nuestra tradición jurídica, en la cual deduciríamos que se trataría de la simulación de una donación, realizada con el sólo objetivo de evitar realizar el trámite de insinuación, y evadir el 242 impuesto a las donaciones. En cambio, para el sistema inglés de los contratos, establecer una consideration nominal no resulta problemático. Lo dicho sólo demuestra la intención clara de las partes de someterse a las reglas del contrato. Por lo demás, los tribunales también pueden sacarle provecho a la regla según la cual los contratos no requieren consideration equitativa, al deducir la existencia de una consideration, aun cuando al parecer las partes no tenían en mente un intercambio o contrato.

La cuarta regla especial sostiene que el acto o promesa de $\mathrm{B}$ debe realizarse al mismo tiempo que el acto o promesa de A. En otras palabras, resulta insuficiente la existencia de consideration en el pasado. Los actos o promesas objeto del contrato deben acordarse y estar vinculados contemporáneamente, sin perjuicio de que su cumplimiento pueda ser diferido. La quinta regla espe- cial señala que hay consideration cuando la obligación a que $\mathrm{B}$ se compromete es una obligación contractual que ya tenía con un tercero. De acuerdo con la segunda regla especial, la obligación a favor de un tercero $(\mathrm{C})$ constituye consideration. Si la obligación de $\mathrm{B}$ con $\mathrm{C}$ es preexistente, $\mathrm{B}$ no estaría sufriendo un nuevo detrimento con la celebración del contrato. Sin embargo, ello no obsta a que la promesa de $\mathrm{B}$ sea consideration para el sistema inglés, porque el hecho de que B tenga esta obligación previa nada tiene que ver con $A$, y éste, a su vez, obtiene el beneficio de tener una acción directa en contra de $\mathrm{B}$ para que este cumpla su obligación a favor de C (p. 134).

De acuerdo con la sexta regla especial, no hay consideration si el acto o promesa de B forma parte de una obligación legal que ya tenía con $\mathrm{A}$, a menos que este último obtenga algún beneficio adicional. Si la obligación legal de B se trata de un deber público, claramente no hay consideration. Sin embargo, cuando la obligación legal tiene un carácter privado, los tribunales han abierto la posibilidad de plantear la existencia de consideration. Por ejemplo, en un caso se estimó que el hecho de que una madre se comprometa a 'cuidar bien y mantener feliz' a su hijo es consideration aun cuando existe un deber legal previo para la madre de cuidar a su hijo. Lord Denning (Alfred Thompson Denning) en este caso sostuvo que aún en este evento el padre obtuvo un beneficio, de la misma manera que habría obtenido un beneficio en caso de que un vecino se comprometiera a cuidar a su hijo ${ }^{16}$.

${ }^{16}$ Ward v Byham [1956] 1 WLR 496 (CA). 
Más discutible resulta el caso en que la obligación preexistente de $\mathrm{B}$ respecto de A es de carácter contractual. Siguiendo la línea de pensamiento de Lord Denning, en un caso se determinó que hay consideration cuando es posible establecer que A ha recibido alguna especie de beneficio práctico con la nueva obligación de $\mathrm{B}^{17}$. Mas, advierte John Cartwright, esta última decisión es controvertida y no está del todo claro si esta relajación de la doctrina de la consideration va a ser o no confirmada por la Corte Suprema (p. 137).

Por último, la séptima regla especial establece que el pago parcial de una deuda no constituye consideration respecto a la condonación del saldo restante. Si A decide condonar a B la totalidad de una deuda por el mero pago parcial de $\mathrm{B}$, no hay consideration respecto al saldo no pagado a menos que A obtenga alguna ventaja adicional, como un pago anticipado o la entrega de algún bien como contrapartida al saldo no pagado. Con todo, este aspecto también podría ser modificado por la Corte Suprema, ya que también podría estimarse que el acreedor que decide aceptar el pago parcial de una deuda obtiene algún beneficio con ello. En particular, es posible que sea preferible recibir una suma de dinero hoy que arriesgarse a que en el futuro ejecutar la deuda sea en la práctica imposible.

\section{EL ESTOPPEL PROMISORIO \\ (O CUASI ESTOPPEL)}

En términos generales, una parte es 'estopped' cuando se le detiene o arre-

${ }^{17}$ Williams v Roffey Bros \& Nicholls (Contractors) Ltd. [1991] 1 QB 1 (CA). bata la posibilidad de negar algo. Por ejemplo, en cualquier litigio no se le permite a ninguna de las partes argumentar que los hechos o el derecho no son como ambos han asumido. En el ámbito contractual, resulta relevante el desarrollo de la jurisprudencia del estoppel promisorio o cuasi estoppel, en el cual una de las partes de un contrato acepta en ausencia de consideration no exigir el cumplimiento de una obligación, generando la legítima expectativa en la contraparte de que no exigirá el cumplimiento de dicha obligación en el futuro.

La consagración de la doctrina del estoppel promisorio en el Derecho inglés se atribuye generalmente a la sentencia de Lord Denning en el caso Central London Property Trust v High Trees House (conocido como High Trees $)^{18}$. El caso tiene que ver con el arriendo a largo plazo de un edificio de departamentos por una renta anual de $£ 2.500$. Durante la guerra, en virtud de que al arrendatario le fue imposible subarrendar la totalidad de los departamentos, el arrendador aceptó reducir la renta anual a $£ 1.500$. Una vez terminada la guerra, y con todos los departamentos subarrendados, el arrendador demanda que la renta anual vuelva a la suma original de $£ 2.500$, pero sólo cobrando dicho valor de renta para el período posterior a la guerra. El tribunal acogió la demanda, en virtud de que las circunstancias que motivaron la rebaja de la renta (la guerra y el hecho de no poder subarrendar todos los departamentos) ya no existían. Pero lo interesante es que Lord Denning advierte que si el

${ }^{18}$ [1947] KB 130 (KB). 
arrendador hubiese demandado el aumento de la renta no sólo por el período posguerra sino, también, por el período en el cual los departamentos no fueron subarrendados en su totalidad, el tribunal no habría acogido esto último. Ello producto de que se entiende en este caso que los saldos de las rentas no percibidas durante la guerra fueron extinguidas por efecto del estoppel promisorio, que consistiría en la representación del arrendador de reducir la renta y el actuar del arrendatario como consecuencia de dicha representación.

Cabe señalar, en primer lugar, que el estoppel promisorio sólo es aplicable para el evento en que se produce una modificación de un contrato preexistente en ausencia de consideration.
En conclusión, esta doctrina supone la existencia de un contrato vigente entre las partes y excluye aquellas modificaciones de contrato que se realizan empleando una nueva consideration (por ejemplo, si ambas partes reducen el monto de sus obligaciones recíprocas). El estoppel promisorio sólo aplica en los casos en que se modifican las obligaciones de una de las partes, y solo cuando dicha modificación implica una reducción de su derecho a exigir el cumplimiento de la obligación de su contraparte.

Otro requisito adicional del estoppel promisorio es la existencia de una 'repreentación' (representation) o promesa, es decir, la intención de una de las partes de no ejecutar total o parcialmente el contrato. Dicha representación puede ser expresa o implícita, pero en ambos casos debe ser clara e inequívoca. Otro elemento esencial del estoppel promisorio es la confianza que se genera como producto de la representación. El hecho de que la contraparte haya hecho algo que no habría hecho de no haber recibido la promesa de la parte que representa de no exigir el cumplimiento de alguna obligación del contrato, es lo que le permite aducir que no está obligada a cumplir dicha obligación. Este cambio en la situación de la parte que argumenta el estoppel promisorio es lo que justifica que se considere injusto exigir el cumplimiento de la obligación en cuestión (p. 144).

Adicionalmente, cabe señalar que el estoppel promisorio por lo general es temporal. En muchos casos la misma representación establece el plazo o condición que debe cumplirse para que la situación excepcional vuelva a la normalidad. Por ejemplo, en High Trees podría considerarse que la representación se mantenía vigente sólo mientras no se acabare la Segunda Guerra Mundial y el arrendatario no lograre subarrendar la totalidad de los departamentos. En aquellos casos en que la representación no establece un plazo o condición, la parte que hizo la representación puede volver a exigir el cumplimiento de la obligación objeto de la representación si notifica a la contraparte dentro de un plazo razonable. Sin embargo, en otros casos la representación es irrevocable. En estos casos, el estoppel promisorio produce el efecto de modificar permanentemente el contrato. Ello ocurre en aquellos supuestos en que la parte a quien se le ha realizado una representación no sólo ha cambiado de circunstancia sino que, además, se encuentra en una situación en la cual no puede razonablemente cumplir la obligación. Por 
ejemplo, A se compromete a entregar a $\mathrm{B}$ cuatro cuadros de un conocido pintor, pero B le indica que sólo necesitará tres cuadros. Mientras A tenga en su poder el cuarto cuadro, B puede cambiar de opinión. Pero si A ha vendido el cuarto cuadro y por ello no puede cumplir la obligación, el tribunal no exigirá dicho cumplimiento.

Una importante característica del estoppel promisorio es que no es una fuente para crear nuevos derechos. En este sentido, la jurisprudencia ha señalado que esta doctrina solo puede operar como un 'escudo' y no como una 'espada' ${ }^{19}$ : puede ser planteada como excepción ante la demanda de la parte que realizó la representación exigiendo el cumplimiento de la obligación, pero no puede ser planteada como acción para exigir el cumplimiento de una obligación que se originaría como consecuencia del estoppel promisorio. De manera tal que la aplicación de esta doctrina en el derecho inglés es acotada de acuerdo con los términos indicados anteriormente, aspecto que lo distingue respecto de otros sistemas del Common Law como Australia y Estados Unidos. Es cierto que permite la condonación de una obligación de una de las partes sin requerir consideration, con lo cual constituiría una excepción a esta última doctrina. Sin embargo, el estoppel promisorio no implica en ningún caso extender "la partida de defunción de la consideration", ${ }^{20}$ como sugiere Jorge López Santa María,

${ }^{19}$ Combe v Combe [1951] 2 KB 215 (CA) 224 (Birkett LJ).

${ }^{20}$ López Santa María (2010b), p. 42. toda vez que la operación del estoppel promisorio se limita a la condonación generalmente temporal de obligaciones contractuales preexistentes, excluyendo el aumento o creación de nuevas obligaciones. Más interesante resulta el paralelo que Jorge López Santa María plantea entre el estoppel promisorio y la doctrina de los actos propios, contenida en los artículos 1468, 1683 y 1685 del Código Civil ${ }^{1}$. Por cierto, es posible afirmar que el estoppel promisorio es una aplicación de este principio, en virtud del cual la parte que realiza un acto de condonación de una obligación no podría contradecir con posterioridad dicho acto que ha generado una expectativa en su contraparte.

Por último, cabe destacar que es posible concebir el estoppel promisorio como una aplicación del principio de buena fe en el cumplimiento del contrato. Si una parte ha realizado una 'representación' a su contraparte, resultaría contrario al principio de buena fe que con posterioridad pretendiera desconocer ese hecho. Se trataría, en consecuencia, de unos de aquellos mecanismos mediante los cuales el sistema inglés de los contratos reconocería parcialmente (o 'por pedazos') el principio general de buena fe contractual.

\section{LOS FACTORES INVALIDANTES O VICIOS DEL CONTRATO}

Los distintos factores invalidantes de los contratos en el Derecho inglés, que

${ }^{21}$ López Santa María (2010b), pp. 42-43. 
podríamos denominar como 'vicios del contrato', son en cierta medida equivalentes a los vicios del consentimiento de nuestro ordenamiento jurídico. Así, v.gr., entre estos vicios del contrato se pueden encontrar los vicios del error (mistake), la coacción o fuerza (duress) y algunas hipótesis asimilables al dolo (misrepresentation). Con todo, el enfoque del Derecho inglés se concentra en la concepción del contrato como un acuerdo objetivamente determinable. De manera tal que, si bien se reconoce que el contrato puede tener vicios similares a nuestros vicios del consentimiento, los tribunales por regla general no emplean el lenguaje de vicios del consentimiento. Incluso, advierte John Cartwright que los manuales de Derecho de los Contratos generalmente no agrupan en un solo capítulo todos estos factores invalidantes. De nuevo nos encontramos con la reticencia del Common Law de seguir las categorías jurídicas generales.

Los factores invalidantes de un contrato en el Derecho inglés son el error (mistake), el 'error inducido' (misrepresentation), la coacción o fuerza (duress), la influencia indebida (undue influence) y el 'negocio desproporcionado' (unconscionable bargain). En el contexto de estos factores invalidantes, el sistema inglés distingue entre contratos 'nulos' (void) y contratos 'anulables' (voidable). Los nulos son aquéllos que no generan derecho u obligación alguna (similar a la noción de inexistencia que se ha planteado en el sistema jurídico chileno). Se considera que estos contratos son nulos desde el comienzo (ab initio), por lo que en ningún momento fueron válidos. El único vicio del contrato que tiene este efecto es el error. Por otra parte, los anulables son aquéllos que adolecen de un vicio desde su formación. Estos contratos crean derechos y obligaciones válidas hasta el momento en que sean declarados nulos. En el contexto de estos vicios anulables, el acto que anula estos contratos se denomina rescisión (rescission). Normalmente los vicios de que adolecen estos contratos son imputables a una de las partes (por ejemplo, la parte que induce al error o quien ejerce la fuerza), por lo cual sólo la parte inocente puede rescindir el contrato. Un aspecto que cabe destacar es que, al igual que nuestra nulidad relativa (art. 1684 del $C C$ ), la rescisión puede ser decretada judicialmente. Sin embargo, a diferencia del sistema jurídico chileno, en algunos casos la rescisión puede ser llevada a cabo de forma directa por la parte afectada por el vicio sin necesidad de recurrir al tribunal. Ello ocurre, en particular, tratándose del error inducido o misrepresentation. La parte que es inducida a error por la contraparte o por un tercero puede rescindir el contrato tan sólo notificando a su contraparte de su intención de rescindir el contrato. Dicha notificación puede realizarse, incluso, mediante la realización de un acto que claramente demuestre esta intención (por ejemplo, devolviendo los bienes objeto del contrato).

Por razones de espacio no es posible estudiar en este trabajo con mayor detalle desde una perspectiva comparada estos vicios del contrato y los mecanismos utilizados para la anulación de los contratos viciados. Pero sería interesante estudiar, por ejemplo, 
la relación entre la figura del error, que muy excepcionalmente permite anular el contrato en el Derecho inglés, y el error inducido, figura que permitiría incluir algunas situaciones contempladas por el dolo en el sistema chileno, pero que no se encuentran reguladas bajo el concepto del error, pese a considerarse también como una falsa representación de la realidad. También resulta interesante el estudio de aquellos vicios que involucran el ejercicio de presión o el abuso de posición para la obtención de un contrato. Se trata de los vicios de coacción o fuerza (duress), la influencia indebida (undue influence) y el 'negocio desproporcionado' (unconscionable bargain). En este ámbito, el sistema inglés parece ser más sensible a este tipo de consideraciones de asimetría contractual que nuestro ordenamiento jurídico. Así, v.gr., se ha discutido la posibilidad de invalidar un contrato por el ejercicio de coacción no sobre la parte contratante o sus parientes, sino, también, sobre intereses económicos (por ejemplo, la amenaza de no cumplir un contrato). Mediante la figura de la influencia indebida los tribunales han desarrollado aún más esta perspectiva, incluyendo hipótesis de abuso de posición. Este vicio del contrato se relaciona con lo comentado más atrás respecto a la doctrina de la consideration, a la cual no le concierne que exista equivalencia entre las prestaciones de las partes, porque el hecho que una de las partes obtenga un beneficio desproporcionado en comparación a la contraparte puede ser considerado por los tribunales como una demostración de la existencia de una influencia indebida ejercida por la parte beneficiada. Por ello es que, a pesar de que el Derecho inglés no contempla un mínimo control de equidad de los contratos, como es la lesión enorme en nuestro ordenamiento jurídico, un contrato que sea sustancialmente inequitativo puede ser invalidado en virtud de la figura de la influencia indebida.

VIII. El CAmbio DE CIRCUNSTANCIAS O IMPREVISIÓN

Durante las distintas etapas de cumplimiento de los contratos pueden ocurrir cambios de las circunstancias en que éstos se originan. Por ejemplo, si nos encontramos ante un cambio de circunstancias que es desconocido por una o ambas partes y es previo a la celebración del contrato, se estaría ante una posible hipótesis de error. Por otra parte, si hay un cambio de circunstancias que es posterior al cumplimiento del contrato, el Derecho de los Contratos nada puede hacer, puesto que ya se han cumplido las obligaciones que son objeto del contrato. Pero, ¿qué ocurre cuando hay un cambio de circunstancias que es posterior a la celebración del contrato, pero previo al cumplimiento de todas las obligaciones del contrato? Se trata del problema conocido entre nosotros como teoría de la imprevisión, en la cual el cambio de circunstancias afecta el balance contractual que existía entre las partes antes del cambio de circunstancias, lo cual puede implicar que el cumplimiento del contrato sea imposible (o excesivamente oneroso) para una de las partes. 
El Derecho inglés en un comienzo adoptó una perspectiva estricta al respecto, no admitiendo excusas para que una de las partes no cumpla el contrato, aun cuando su cumplimiento resulta imposible por un hecho ajeno a la parte. Sin embargo, a partir de la segunda mitad del siglo XIX, los tribunales desarrollaron la doctrina de la frustración (frustration). IEn un principio esta doctrina se concibió como una cláusula implícita (véase supra III), entendiéndose incorporada en los contratos que éstos no son obligatorios si su cumplimiento resulta imposible para cualquiera de las partes ${ }^{22}$. Esta idea fue rechazada con posterioridad por Lord Radcliffe (Cyril John Radcliffe) en el caso Davis Contractors Ltd v Fareham UDC $^{23}$, toda vez que es problemático suponer una intención implícita de las partes respecto a algo que por definición no previeron al momento de celebrar el contrato. En su reemplazo, Lord Radcliffe sostiene que cuando ocurre un evento imprevisto debe atenderse no a la intención de las partes, sino a los términos que un hombre medio razonable hipotéticamente habría acordado respecto a los distintos derechos y responsabilidades que les correspondería a las partes como resultado del imprevisto. Esta fórmula de la doctrina de la frustración es la que se encuentra vigente.

En primer lugar, cabe señalar que la doctrina de la frustración requiere que las partes no hayan contemplado en las cláusulas del contrato la ocu-

${ }^{22} \mathrm{El}$ caso que consagró la doctrina de la frustración concebida en estos términos es Taylor v Caldwell (1863) 3 B \& S 826, 122 ER 309.

${ }^{23}$ [1956] AC 696 (HL). rrencia del imprevisto, y que dicho imprevisto cambie radicalmente la naturaleza de las obligaciones del contrato (p. 255). Desde luego, es posible para las partes regular la ocurrencia de imprevistos durante el cumplimiento del contrato, lo cual puede realizarse mediante cláusulas de 'fuerza mayor' o ' $h a r d s h i{ }^{24}$. En el evento que el contrato contenga estas cláusulas, la doctrina de la frustración no es aplicable. Sin embargo, cabe señalar que el ámbito de la doctrina de la frustración es restringido, y no cubre aquellos casos en que hay una excesiva onerosidad sobreviniente como consecuencia del imprevisto. Los tribunales han enfatizado que el aumento significativo del costo de cumplir un contrato para una de las partes no es un antecedente suficiente para la aplicación de la doctrina de la frustración. En el mencionado caso Contractors Ltd v Fareham UDC, la House of Lords (hoy Corte Suprema) rechazó en forma unánime esta posibilidad, señalando que el cambio de circunstancias debe implicar un cambio en la obligación de tal magnitud que, de cumplirse, constituiría una obligación distinta a la que originalmente la parte afectada se comprometió ${ }^{25}$. En consecuencia, el sistema inglés excluye la revisión del contrato por excesiva onerosidad sobreviniente para las prestaciones de una de las partes, y sólo constituye una solución para casos de caso fortuito o fuerza mayor.

Por último, cabe mencionar que de ser aplicable la doctrina de la frustra-

${ }^{24}$ Jorge López Santa María discute estas cláusulas en LóPez Santa María (2010a), pp. 266-274.

${ }^{25}$ [1956] AC 696 (HL) 729 (Lord Radcliffe). 
ción, el resultado es la terminación del contrato. Dicha terminación sólo tiene efectos para el futuro, no es retroactiva. Por medio de la legislación, se han establecido algunos mecanismos de compensación para la parte que ya ha cumplido su obligación antes del cambio de circunstancias, y que se ve afectada por la terminación del contrato (ya que, producto de la terminación, la contraparte no cumplirá su obligación correlativa) ${ }^{26}$.

\section{ACCIONES DE RESPONSABILIDAD POR INCUMPLIMIENTO CONTRACTUAL}

El enfoque del sistema inglés en relación con la responsabilidad contractual se concentra en remediar el incumplimiento de contrato. Como consecuencia de este enfoque, los tribunales son reticentes a forzar el cumplimiento de un contrato, convirtiendo a la indemnización de perjuicios en la regla general y el cumplimiento forzado en la excepción. Para el Derecho inglés, la obligación contractual se compone de obligaciones primarias, que consisten en el cumplimiento de las prestaciones involucradas, y obligaciones secundarias, que consisten en los remedios que persiguen reparar el incumplimiento contractual, siendo el principal de ellos la obligación secundaria de indemnizar a la contraparte por los perjuicios originados por el incumplimiento de la obligación primaria.

El catálogo de acciones o remedios de responsabilidad contractual contempla no sólo la indemnización 1943.
${ }^{26}$ Law Reform (Frustrated Contracts) Act de perjuicios, sino, también, el cumplimiento forzado del contrato y la resolución por incumplimiento de contrato. En el presente trabajo me concentro en la indemnización de perjuicios. No obstante, cabe destacar respecto al cumplimiento forzado del contrato su carácter excepcional; sólo será decretado por un tribunal en el evento que la indemnización de perjuicios se considere como un mecanismo inadecuado para la reparación del daño (por ejemplo, tratándose de un bien único respecto al cual no hay un mercado). En cuanto a la resolución del contrato, resulta interesante destacar que esta acción no requiere de declaración judicial, sino que se trata de un derecho que la parte diligente puede ejercer notificando a su contraparte, sin necesidad de otorgar un mayor plazo para el cumplimiento del contrato. Resulta interesante este mecanismo otorgado a la parte diligente del contrato, puesto que le permite remediar (o evitar) lo antes posible los perjuicios que un incumplimiento contractual le podrían generar, por ejemplo, buscando de inmediato otro proveedor del bien o servicio en cuestión. Esto le permite al sistema jurídico remediar de manera más inmediata y efectiva la situación de la parte diligente.

El principio fundamental de la indemnización de perjuicios en el ámbito contractual consiste en situar a la parte afectada por el incumplimiento en la misma posición en que ésta se encontraría si el contrato se hubiera cumplido. En otras palabras, la indemnización de perjuicios persigue satisfacer la expectativa que tenía el contratante diligente de que el con- 
trato se cumpliera adecuada y oportunamente. Con todo, los tribunales han señalado que esta expectativa tiene límites. En Ruxley Electronics \& Construction Ltd v Forsyth, ${ }^{27}$ el demandante (Forsyth) contrató a la empresa Ruxley para la construcción de una piscina de 2,3 $\mathrm{m}$ de profundidad por la suma de $£ 18.000$. Sin embargo, Ruxley construyó la piscina con 1,8 m de profundidad. El costo de destruir la piscina y volver a construirla era de $£ 21.560$, pero se demostró que no había diferencia de valor alguno entre la piscina efectivamente construida y una piscina de $2,3 \mathrm{~m}$ de profundidad. En este caso, el punto crucial era determinar la naturaleza del perjuicio indemnizable: cंse trata del costo de destruir y volver a construir la piscina, o de la diferencia de valor económico entre la piscina efectivamente construida y la piscina construida de acuerdo con las especificaciones del contrato? La House of Lords aceptó la regla general según la cual satisfacer la expectativa del demandante implica indemnizar el costo de reparar el defecto (en este caso, destruir y volver a construir la piscina). Sin embargo, la House of Lords estableció que no se trata de una regla absoluta, dejando en claro que este tipo de indemnización debe ser razonable. En el preciso caso de Ruxley, se estimó que no era razonable exigir la reparación del defecto, puesto que el juez de primera instancia determinó que el mismo demandante, aun cuando recibiera la indemnización, no incurriría en los gastos necesarios para destruir y volver a construir la piscina. De esta ma-

$$
{ }^{27} \text { [1996] AC } 344 \text { (HL). }
$$

nera, la House of Lords estableció que la indemnización de perjuicios no puede otorgar un beneficio excesivo al demandante ni constituir un castigo o sanción para la parte incumplidora. John Cartwright sostiene que esta decisión es consecuente con la reticencia de los tribunales a otorgar el cumplimiento forzado de los contratos, en razón de que en muchos casos no es razonable exigir el cumplimiento del contrato cuando ello implicaría incurrir en gastos adicionales innecesarios, constituyendo una sanción o beneficio excesivo para el demandado (p. 280).

Teniendo presente este enfoque económico de la indemnización de perjuicios, se comprende la razón por la cual el sistema inglés restringe la indemnización del daño moral, aunque sin excluirla totalmente. En este sentido, en Ruxley la House of Lords acogió la indemnización de $£ 2.500$ a título de daño moral ('loss of amenity') que había sido decretada por el juez en primera instancia. No obstante, señalaron que la indemnización del daño moral tiene un carácter excepcional. De acuerdo con la jurisprudencia de la House of Lords, el daño moral es indemnizable sólo en aquellos casos en que el contrato tiene como objetivo principal (o importante) dar placer, descanso o tranquilidad. Pero los montos deben ser moderados, por lo que no se encontrarán en el sistema inglés casos en los cuales altas sumas de dinero son indemnizadas a título de daño moral.

El sistema inglés contempla una interesante hipótesis de indemnización de perjuicios que no ha sido planteada en el ordenamiento jurídico chileno. Se 
trata de la restitución de las ganancias obtenidas por la parte incumplidora como consecuencia de su incumplimiento. En el Derecho inglés, la regla general es que la parte que incumple un contrato sólo debe indemnizar los daños causados a su contraparte, y no los beneficios que ilegítimamente obtuvo como resultado de dicho incumplimiento. Sin embargo, la House of Lords abrió esta posibilidad en el caso Attorney-General v Blake ${ }^{28}$, en el cual el demandado fue condenado a restituir ganancias por la publicación de un libro que contenía información confidencial (objeto de una cláusula de confidencialidad). Ahora bien, la jurisprudencia ha señalado que este mecanismo tiene un carácter excepcional, aplicable sólo en caso que la indemnización de perjuicios o el cumplimiento forzoso sean inadecuados. De tal manera que no es posible solicitar la indemnización de perjuicios juntamente con la restitución de ganancias.

A pesar de que al parecer el ámbito de aplicación del caso Blake no está del todo determinado (p. 283), resulta interesante plantear esta hipótesis cuando no le es posible al demandante probar que sufrió directamente un daño como resultado del incumplimiento contractual, como ocurría en este caso. Por cierto, en el sistema jurídico chileno sólo sería posible obtener indemnización de perjuicios si el demandante prueba que sufrió un daño. En el caso Blake, el demandante tendría que demostrar que sufrió un perjuicio con la divulgación de la información confidencial. Una posible vía para probar esto sería el lucro

$$
{ }^{28} \text { [2001] } 1 \text { AC } 268 \text { (HL). }
$$

cesante, esto es, el beneficio que el demandante podría haber percibido en caso de publicar la información. Esta solución sería coherente con la posición que los tribunales ingleses han adoptado frente a otros casos, en los cuales se ha utilizado como base de cálculo para determinar el monto a indemnizar el beneficio obtenido por el demandado como consecuencia del incumplimiento, pero con el expreso propósito de reparar los daños sufridos por el demandante y no restituir las ganancias que obtuvo el demandado ${ }^{29}$. Sin embargo, en el caso particular de Blake el demandante era una agencia de seguridad que no tenía un interés patrimonial en revelar la información, por lo que esta vía no sería aplicable en ese caso. Otra solución más controvertida en el sistema chileno sería demostrar que el demandante sufrió alguna especie de daño moral. Sin duda, se trata de un aspecto que vale la pena estudiar en el derecho chileno.

Un último aspecto relevante a destacar tiene que ver con la utilización de cláusulas penales. En el Derecho inglés, estas cláusulas no tienen validez en la medida en que se establezca una pena como corolario del incumplimiento. La razón de ello es que el sistema no concibe el incumplimiento de un con-

${ }^{29}$ Wrotham Park Co Ltd v Parkside Homes Ltd [1974] 1 WLR 798 (Ch). En este caso se determinó el monto de la indemnización mediante un porcentaje de las ganancias obtenidas por el demandado, pero con el propósito de calcular el monto que razonablemente se esperaría que las partes hubieran negociado para modificar la cláusula del contrato que fue violada. En este sentido, el tribunal señaló que la indemnización correspondía a la pérdida del derecho del demandante a negociar esta modificación del contrato. 
trato como algo reprochable; por ende, se considera que la parte incumplidora no debiera ser sancionada, sino sólo condenada a indemnizar los perjuicios que se originen como consecuencia del incumplimiento. De manera tal que en el Derecho inglés hay una mayor libertad para incumplir los contratos que en la mayoría de los sistemas continentales. Sin perjuicio de lo anterior, se permite que las partes acuerden avaluaciones anticipadas de perjuicios, siempre y cuando dichas avaluaciones no tengan por objetivo penalizar el incumplimiento.

El estudio de las acciones de responsabilidad contractual da cuenta de elementos esenciales del Derecho inglés de los contratos en general. En particular, revela la concepción del contrato como el resultado de una negociación en que los factores económicos representan un papel crucial. De esta concepción económica se deriva que la indemnización de perjuicios sea la regla general y el cumplimiento forzado la excepción. Esto también explica el carácter de la indemnización de perjuicios, dirigida a satisfacer la expectativa (normalmente económica) que la parte diligente tenía respecto al cumplimiento del contrato. Asimismo, esta concepción también explica la razón por la cual el sistema inglés evita sancionar a la parte incumplidora y otorgar beneficios excesivos a la parte diligente, lo cual puede verse reflejado como vimos en la naturaleza de los perjuicios indemnizables, y en el rechazo de las cláusulas penales. Si bien pudiera pensarse que con ello el sistema inglés no protege adecuadamente a los intereses de la parte diligente, por otra parte, también puede argumentarse que el Derecho inglés protege de manera más eficaz e inmediata tales intereses, otorgando a la parte diligente la posibilidad resolver el contrato sin que se requiera declaración judicial previa, lo cual le permite al contratante buscar alternativas lo antes posible para satisfacer su expectativa.

\section{Conclusiones}

Es indudable que la obra de John Cartwright constituye una herramienta indispensable para el abogado proveniente de una tradición jurídica continental. La lectura del libro es accesible, a pesar de incluir temas complejos y que han sido desarrollados en múltiples casos. Un atributo importante de la obra es su estructura y orden para analizar los distintos aspectos del Derecho de los Contratos, que es similar a la estructura de un manual de la materia en un sistema jurídico continental. Por ello es que John Cartwright discute los remedios que provee el sistema inglés para la ruptura de tratativas preliminares de un contrato, o agrupa en un solo lugar los factores que pueden invalidar un contrato. De manera tal que el libro nos presenta un sistema contractual atractivo, cuya esencia es una expresión de la cultura jurídica del Common Law, y consiste en la concepción del contrato como el resultado de una negociación entre las partes. John Cartwright demuestra que, a pesar de la reticencia del Common Law a adoptar categorías jurídicas generales, el sistema inglés ofrece interesantes soluciones particulares a los problemas 
del Derecho de los Contratos. Dichas soluciones en muchos casos se asemejan a las soluciones adoptadas por los sistemas continentales por medio de las categorías jurídicas generales. Sin embargo, en otros casos, las soluciones particulares son distintas, e invitan a reflexionar acerca de cómo ellas podrían encuadrarse dentro de un sistema jurídico continental como el chileno.

\section{BibLIOGRAFÍA CITADA}

Barros Bourie, Enrique (2006). Tratado de Responsabilidad Extracontractual. Santiago: Editorial Jurídica de Chile. Burrows, Andrew (2013). English Private Law. $3^{\text {a }}$ ed. Oxford: Oxford University Press.

Cartwright, John (2013). Contract Law. An Introduction to the English Law of Contract for the Civil Lawyer. $2^{\mathrm{a}} \mathrm{ed}$. Oxford: Hart Publishing.
LÓPEZ SANTA María, Jorge (2010a). Los Contratos. Parte General. $5^{\mathrm{a}}$ ed. actualizada por Fabián Elorriaga de Bonis. Santiago: Legal Publishing.

López Santa María, Jorge (2010b). "Causa y 'consideration' en los contratos", en Raúl Tavolari Oliveros, (ed), Doctrinas esenciales. Derecho Civil. Contratos. Santiago: Editorial Jurídica, tomo I.

Weinrib, Ernest (2012). The Idea of Private Law. $2^{\mathrm{a}}$ ed. revised. Oxford: Oxford University Press.

\section{Normas citadas}

Consumer Credit Act 1974.

Law of Property (Miscellaneous Provisions) Act 1989.

Law Reform (Frustrated Contracts) Act 1943.

Sale of Goods Act 1979.

Supply of Goods and Services Act 1982.

WinsCHEID. 